\title{
Country Characteristics and Preferences over Tax Principles
}

\author{
Nigar Hashimzade \\ Hassan Khodavaisi \\ University of Exeter \\ University of Urmia \\ Gareth D. Myles \\ University of Exeter and Institute for Fiscal Studies
}

October 6, 2006

\begin{abstract}
The European Union has long maintained an intention to move to the origin principle of taxation but no progress has been made since the completion of the single market. The lack of progress seems surprising given the significant support for the origin principle in the economic literature. However, there is a contrast between the European Union that contains countries of widely different sizes and productivity levels and the theoretical literature that has focussed on models with symmetrical countries. We extend the modelling of preferences over tax principles to incorporate asymmetries in efficiency and size. We show that disagreement among countries over tax principles can be sustained even with close economic integration. Large countries and inefficient countries are shown to prefer the origin principle. In contrast, small countries and efficient countries can have a preference for the destination principle. These results provide an insight into the political economy of the impasse in European Union tax policy.
\end{abstract}

Keywords: tax principles, international taxation, imperfect competition. JEL-Classification: F12, H20.

Acknowledgements: Thanks are due seminar audiences in Athens, Durham and Leicester.

Correspondence to: Nigar Hashimzade, Department of Economics, University of Exeter, Exeter EX4 4PU, UK. e-mail: n.hashimzade@ex.ac.uk 


\section{Introduction}

The completion of the single market in January 1993 had a significant impact upon tax policy in the European Union. Prior to the completion of the single market the system of taxation involved exports from one member state to another being zero-rated. Importers paid VAT at the rate of the destination country in which final consumption took place. For this system to work, the tax authorities had to be able to determine when goods crossed borders. The removal of borders ensured that there was no documentary trail on which tax liabilities could be determined. The European Commission's White Paper of 1987 proposed that after the abolition of border controls European Union procedures would mirror national ones. Exports would carry the VAT of the origin country, which could be reclaimed as input VAT in the destination country if the good was used as an input rather than a consumption good. The VAT charged to the final consumer would still be that of the destination country and a "Clearing House" would reallocate revenues to the appropriate country. This proposal was never implemented. Because of the administrative problems which it generates, an interim scheme is currently in operation which attempts to mirror the pre1993 zero-rating of exports. It does this by substituting account auditing for the role previously performed at frontier controls. It was initially foreseen that the interim procedure would be replaced by the "definitive" system by 1997 . This has still not happened. In fact, the nature of the definitive system has not yet even been determined and discussions about the future functioning of VAT continue.

The method of taxation employed prior to the completion of the single market is known as the destination principle. Under this principle commodities are taxed in the country of final consumption. Exports are tax free, with taxes imposed once the border is crossed. Consequently, the destination principle requires the maintenance of borders so that the appropriate border tax adjustments can be made. The fact that the destination principle is not a suitable system of taxation in a single market was recognized at a very early point in the development of the European Union. The Tinbergen Report of 1953 recognized that the destination principle would not be sustainable once the single market was completed. The alternative system of taxation proposed by Tinbergen was the origin principle under which goods are taxed in the country of production. When applied to the European Union, the origin principle would require each member state to tax the production occurring within its borders. The advantage of the origin principle is that no border tax adjustments are required so that it is consistent with the operation of a single market (in that tax differentials do not induce cross-border shopping) and it leaves each member state free to pursue its own tax objectives.

The switch to the origin principle of taxation has long been established as a goal of European Union tax policy. A recent statement of support for this position was contained in Amendment 2, Recital 5 of the 2003 Draft Report of the Committee on Monetary and Economic Affairs. The relevant passage states that: 
The Community's long term objective is moving to a definitive VAT system, based on the principle of taxation in the country of origin, this implies that there should be a gradual continuation of a systematic and coherent approach towards approximation of VAT rates, as needed.

The implementation of the switch from the destination principle to the origin principle requires political agreement within the European Union. A reading of the existing academic literature makes it difficult to understand why such agreement is not readily forthcoming. If the world is viewed as approximating the competitive ideal then the literature provides some very general results establishing equivalence between the two principles (Tinbergen 1953, Lockwood et al. (1994a, b). Alternatively, research that analyzes imperfect competition (Keen and Lahiri 1998, Haufler et al. 2005, Hashimzade et al. 2005) has shown a robust preference for the origin principle - at least when there are limited barriers to trade. The key assumption of these papers is that of symmetry between countries. As a consequence, there can never be disagreement between the countries on the preferred tax principle. A credible argument can be made that the countries in the European Union are not symmetric. Countries range in population size from Malta and Luxembourg with less than half a million to Germany with eighty two million. There is also a significant range of productivity levels with Luxembourg approximately six times more efficient than Czech Republic. ${ }^{1}$ These observations reveal a clear need to test whether the conclusion of a preference for the origin principle is robust to these asymmetries. Keen and Lahiri (1998) have made some progress in this regard, but their results apply only when there is complete economic integration and Cournot competition between firms.

In this paper we extend the analysis of the choice between tax principles to incorporate asymmetries in efficiency (modelled by the marginal cost of production) and in country size (modelled by the number of consumers). This allows us to relate country characteristics to the preference for tax principle, and gives some idea of how the political economy of tax negotiation in the European Union will unfold. In addition, we also relate the results to market structure, the degree of product differentiation, and the extent of economic integration.

The central finding is that there can exist situations where countries cannot reach agreement on tax principle. This lack of agreement is a direct consequence of asymmetry and is possible with both Cournot and Bertrand competition between firms. With Cournot competition the countries will converge on a preference for the origin principle as economic integration proceeds. This need not be the case with Bertrand competition: disagreement can remain even with complete integration. In brief, large countries and inefficient countries prefer the origin principle. The preference of small countries and efficient countries depends on the parameter configuration. Any disagreement between countries

\footnotetext{
${ }^{1}$ Productivity is measured by GDP per hour worked; in 2004 across European Union countries this varied from 68.18 (Luxembourg) to 11.32 (Czech Republic) US dollars per hour (data obtained from Eurostat and IMF).
} 
is removed by economic integration if competition between firms is in quantities or the efficiency difference not too large. But disagreement over the preferred principle resulting from size differences is not removed by economic integration. Therefore, country size is a fundamental source of disagreement over the choice of tax principle.

The paper is structured as follows. In Section 2 we describe the model used in this paper. Section 3 relates the preference over tax principles to efficiency in production. Section 4 relates the preference over tax principles to country size. Section 5 provides conclusions. The formal derivation of the result requires quite extensive computation. Rather then burden the presentation with the details it seemed preferable to place the details in a companion paper where they can be developed fully. This companion paper can be downloaded from www.people.ex.ac.uk/gdmyles/papers/pdfs/CounCharComp.pdf.

\section{Description of Model}

The analysis is aimed at understanding the implications of country asymmetries for the preferred form of international tax principle. The conclusion that has been reached in symmetric models - that the origin principle is preferable-has to be tested for robustness. This is particularly important if the result is to be used to inform policy debate in the European Union context given the considerable asymmetries among member states. We choose to focus upon asymmetries arising from size and productivity, and use a simple parametric representation of each of these in the economic modelling.

The important characteristic of the model we analyze is trade conducted under conditions of imperfect competition between firms producing differentiated products. Moreover, we combine this with asymmetry between countries. The model we employ is developed from Keen and Lahiri (1998) and Haufler et al. (2005) and Hashimzade et al. (2005). We extend the basic model by considering alternative forms of imperfect competition (Cournot competition in quantities, and Bertrand competition in prices), admitting product differentiation, and permitting asymmetries. Asymmetries in size are represented by the countries having different numbers of consumers, and asymmetries in productivity are represented by differences in the marginal cost of production. These choices are intended to capture in a simple way two of the basic characteristics that differentiate member states of the European Union.

The tax principles are contrasted by determining the level of welfare each country achieves when levying taxes which are optimal. The taxes are chosen non-cooperatively taking into account the equilibrium that is achieved through the interaction of the imperfectly competitive firms. The contrast is undertaken for a range of the parameters reflecting the asymmetries. In addition, we also consider how the choice between principles is related to the extent of economic integration. This latter variable is represented by the level of trade cost in shipping products between countries. The trade cost can be viewed as measuring the entire set of impediments to trade with the interpretation that they will be 
reduced by increased economic integration.

We consider two countries to which we give the labels "home" and "foreign". There are three consumption goods, denoted $X, Y$, and $Z$. Good $X$ is produced by a firm located in the home country and good $Y$ by a firm located in the foreign country. These goods are variants of a single differentiated product. The two firms compete using either quantities or prices as the strategic variable. The third good, $Z$, is produced by competitive firms located (potentially) in both countries and is freely and costlessly traded. All goods are produced using labor as the only input. Each unit of good $Z$ requires one unit of labor. The production of good $X$ requires payment of a fixed cost, $F$, and and a marginal cost, $c$. The fixed cost and marginal cost for good $Y$ are $F^{*}$ and $c^{*}$ respectively. The export of a unit of good $X$ or good $Y$ involves a trade cost of $s$. Good $Z$ is chosen as the numeraire with price equal to one which, when combined with the technology for producing $Z$, implies the wage rate in both countries is also one.

There are $n$ consumers in the home country and $n^{*}$ consumers in the foreign country. Each consumer supplies labor and receives an equal share of the profit of the firm in their country of location. A fixed quantity of labor, $L$, is supplied inelastically by each consumer and there is no disutility of labor supply. The tax revenue raised by each government is returned as a lump-sum to their residents.

The government in the home country levies a specific tax of value $t$ on the differentiated product (and the foreign government a tax of value $t^{*}$ ). There is no tax on the numeraire commodity, $Z$, so standard equivalence results do not apply. When the destination principle is applied the specific tax is levied upon the quantity consumed in each country. Under the origin principle the tax is levied on the output in each country. The taxes are chosen non-cooperatively to maximize national welfare which is defined as the sum of profit of resident firms and utility of resident consumers.

We denote by $x$ the quantity consumed in the home country of the output of the home firm, and by $y^{*}$ the quantity of the foreign firm's output consumed in the home country. Each home consumer chooses the quantities $x$ and $y^{*}$ to maximize the quasi-linear utility function (adapted from Vives (1984))

$$
U\left(x, y^{*} ; \gamma\right)+Z=\left(x+y^{*}\right)-\frac{1}{2}\left(x^{2}+2 \gamma x y^{*}+y^{* 2}\right)+Z,
$$

subject to the budget constraint

$$
p_{x} x+p_{y^{*}} y^{*}+Z=L+T,
$$

where $p_{x}$ and $p_{y^{*}}$ are prices, and $T$ is the lump-sum transfer received. The parameter $\gamma, 0 \leq \gamma \leq 1$, measures the degree of differentiation between the products. A higher value of $\gamma$ implies a lower degree of product differentiation, so if $\gamma=1$ consumers perceive the products as perfect substitutes. The profit level of the home firm under the destination principle is

$$
\pi^{D}=n\left(p_{x}-t-c\right) x+n^{*}\left(p_{x^{*}}-t^{*}-s-c\right) x^{*}-F,
$$


and national welfare is

$$
W^{D}=n\left[U\left(x, y^{*} ; \gamma\right)+Z\right]+\pi^{D} .
$$

Under the origin principle production is taxed at source so profit becomes

$$
\pi^{O}=n\left(p_{x}-t-c\right) x+n^{*}\left(p_{x^{*}}-t-s-c\right) x^{*}-F,
$$

and national welfare is

$$
W^{O}=n\left[U\left(x, y^{*} ; \gamma\right)+Z\right]+\pi^{O} .
$$

Equivalent expressions apply for utility $\left(U^{*}\right)$, profit $\left(\pi^{*}\right)$ and welfare $\left(W^{*}\right)$ in the foreign country under the two principles.

To provide a basis for comparison we assume that $c^{*}=0$ and $n^{*}=1$. Therefore, a value of $c>0$ represents the home country being less efficient than the foreign country, and a value of $n<1$ represents a home country that is smaller than the foreign country. These two parameters capture the asymmetry between the countries. A smaller value of $s$ reflects greater economic integration, with $s=0$ denoting complete integration with zero trade costs. The value of $\gamma$ is determined by preferences but it interacts with the imperfect competition to determine the degree of market power enjoyed by the imperfectly competitive firms. Our discussion focuses primarily upon the roles of $c$ and $n$, but we also relate the results to the values of $s$ and $\gamma$.

\section{Cost Asymmetry}

This section analyzes the effect that an asymmetry in production efficiency has upon the preferred form of tax principle. It should be recalled that the analysis of the symmetric case (Keen and Lahiri, 1998, Haufler et al., 2005, Hashimzade et al., 2005) has demonstrated a robust preference for origin taxation. This applies for both Bertrand and Cournot competition, and for a range of demand systems, if trade costs are sufficiently low. Consequently, if these symmetric models were a correct description of the European Union, unanimity in favor of the origin principle should eventually be achieved by economic integration.

The home country produces with a positive marginal cost and in the following discussion is referred to as the "high cost" country. The foreign country, which has a marginal cost of zero, is referred to as the "low cost" country. To isolate the effect of the cost asymmetry it is assumed in this section that the countries have the same population. Hence, $n=n^{*}=1$. The comparison of tax principles is conducted first for Cournot competition and then for Bertrand competition.

\subsection{Cournot competition}

The countries choose their tax rates non-cooperatively to maximize national welfare. The firms take the taxes as given when they maximize profit. With 
Cournot competition the firms compete using output levels as strategic variables. The home firm chooses the pair $\left\{x, x^{*}\right\}$ and the foreign firm chooses the pair $\left\{y, y^{*}\right\}$. Throughout the analysis we restrict our attention to values of the parameters $\{c, s, \gamma\}$ that result in positive values for the choice variables of the firms.

When the two-stage game is solved with the destination principle the optimal taxes are given by

$$
t_{C}^{D}=\frac{c-s}{2(2-\gamma)}, \quad t_{C}^{* D}=-\frac{s+c}{2(2-\gamma)}
$$

where the subscript $C$ refers to Cournot competition and the superscript $D$ refers to the destination principle. It can be seen that the tax in the high cost country is negative for high values of $s$ but positive for low values. The tax in the low cost country is negative for all $s$ and $c$. The tax differential, $t_{C}^{D}-t_{C}^{* D}$, is always positive and is proportional to the production cost differential. Hence, the low cost country always provides a larger subsidy. The explanation for the use of subsidies is the correction of the under-competition caused by imperfect competition leading to a price in excess of marginal cost. In the absence of any trade costs the more efficient firm (located in the low cost country) would be subsidized more relative to the less efficient firm. Trade costs partly mitigate this effect, but the essence of the policy can be seen in the optimal taxes.

Repeating the analysis of the two-stage game for the origin principle the optimal taxes are

$$
\begin{aligned}
t_{C}^{O} & =\frac{1}{6+3 \gamma-\gamma^{2}}\left(\frac{\left(4-\gamma^{2}\right)\left(3+\gamma^{2}\right) c}{6-3 \gamma-\gamma^{2}}+\frac{2 \gamma^{2} s}{2-\gamma}-2-\gamma-\gamma^{2}\right) \\
t_{C}^{* O} & =\frac{1}{6+3 \gamma-\gamma^{2}}\left(\frac{2 \gamma^{2} s}{2-\gamma}-\frac{4 \gamma^{3} c}{6-3 \gamma-\gamma^{2}}-2-\gamma-\gamma^{2}\right)
\end{aligned}
$$

where the superscript $O$ refers to the origin principle. In the region in which the output levels are positive both of these taxes are negative. The two countries therefore subsidize national production. It can also be seen that the low cost country always provides a higher subsidy and that the tax differential is again proportional to $c$. The optimality of a subsidy is the standard result in the strategic trade literature (Brander and Spencer, 1985). The fact that the more efficient firm receives a higher subsidy is explained by Neary (1994) through the argument that it has a comparative advantage in generating profit and hence the payoff to the subsidy is greater.

The values for the optimal taxes can be used to conduct a welfare comparison of the two tax principles. The comparison is achieved by calculating the difference between the level of welfare with the optimal origin taxes and the level of welfare with the optimal destination taxes. The welfare difference for the high cost country is defined by

$$
\mu_{C}(\gamma, c, s) \equiv W^{O}-W^{D}
$$




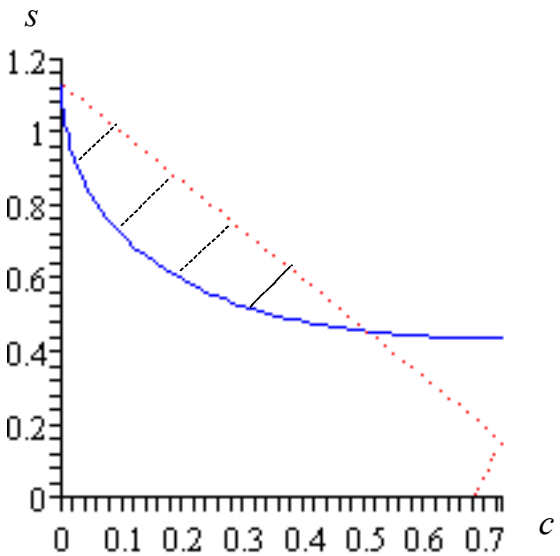

Figure 1: Preferences of the low-cost country (Cournot, $\gamma=0.3$ )

and the welfare difference for the low cost country by

$$
\mu_{C}^{*}(\gamma, c, s) \equiv W^{* O}-W^{* D}
$$

Using the solutions for the optimal taxes these welfare differences can be expressed as quadratic polynomials in the trade cost, $s$. An analysis of the coefficients of the polynomials then permits a complete characterization of the possible values of the differences.

The first result is that the welfare difference for the high cost country is always positive for all values of $\gamma, c$, and $s$ for which the output levels are positive. Therefore, the origin principle is always favored by the high cost country. This finding is in line with earlier results for the symmetric case that have demonstrated a preference for the origin principle.

The welfare difference for the low-cost country has a more complex structure. For each value of $\gamma$ there is a critical value of $s$ (which depends on $\gamma$ ). The welfare difference is positive for any value of $s$ below this critical value. The low- cost country therefore prefers the origin principle when trade costs are low. For values of $s$ above this critical value the welfare difference is positive for low values of $c$, but negative for high values of $c$. Therefore when the countries are similar ( $c$ low) the low-cost country retains a preference for the origin principle even with high trade costs. However, when there is sufficient asymmetry ( $c$ high) the low-cost country prefers the destination regime. This reasoning in summarized in Figure 1. The dotted line is the boundary of the set of parameter values for which all quantities are positive. Below the curve the low-cost country prefers the origin principle. The destination principle is preferred in the cross-hatched area above the curve.

These results have two implications. First, there will be agreement over the choice of tax principle if there is close economic integration. This conclusion 
mirrors the preference for the origin principle found in the symmetric case. Second, a lack of integration linked with sufficient asymmetry can lead to a divergence in preferences over tax principles with the low-cost country preferring the destination principle. The preference for one principle over the other can therefore be correlated with efficiency in production. Furthermore, contrary to the predictions of the symmetric model, there is no necessity for unanimity in choice of principle.

At this stage we summarize the consequences of introducing asymmetry. We have shown that in an integrated economy, introducing asymmetry has no effect in comparison with the symmetric model since both the low and the high cost country prefer the origin to the destination principle. When economic integration is not complete we have shown that the high cost country always prefers the origin principle while the low cost country may prefer the destination principle. Therefore, asymmetry can mean agreement on a tax principle is difficult to achieve. The policy implication of the above analysis is that only by achieving complete integration we can ensure agreement.

\subsection{Bertrand competition}

In this section we conduct a similar comparison of the origin and the destination principles for Bertrand competition with price as the strategic variable. The firm located in the home country now chooses the pair of prices $\left\{p_{x}, p_{x^{*}}\right\}$ and the firm in the foreign country chooses the pair $\left\{p_{y}, p_{y^{*}}\right\}$. We again restrict attention to the set of parameter values $\{c, s, \gamma\}$ for which prices are positive. It will become clear that the comparison for Bertrand competition differs significantly from that for Cournot competition.

Maximizing the welfare levels of the two countries while taking into account the reactions of the firms generates the optimal taxes for the destination principle

$$
t_{B}^{D}=\frac{(1+\gamma)(c-s)}{2(\gamma+2)}, \quad t_{B}^{* D}=-\frac{(1+\gamma)(c+s)}{2(\gamma+2)},
$$

where the subscript $B$ denotes Bertrand competition. These expressions show that the high-cost country sets a positive tax when $s<c$, a zero tax when $s=c$, and a negative tax when $s>c$. The optimal tax is always negative for the low-cost country.

Notice that for the maximal degree of product differentiation $(\gamma=0)$ the nationally optimal taxes in the high-cost and the low-cost countries are identical for Cournot and Bertrand competition. Therefore it does not matter for the value of the taxes whether firms compete with prices or quantities as strategic variables. However, for the minimal degree of product differentiation $(\gamma=1)$, the nationally optimal tax in the high-cost country is greater in the case of Cournot competition than it is for Bertrand competition. This is because in the Bertrand case the more intensive competition corrects part of the inefficiency of imperfect competition. For the same reason the level of subsidy in the lowcost country is greater in the case of Cournot competition than in Bertrand competition. 
Repeating the analysis of welfare maximization for the origin principle the optimal taxes are

$$
\begin{aligned}
t_{B}^{O}= & \left(\frac{\left(12-23 \gamma^{2}+9 \gamma^{4}\right) c}{6+3 \gamma-\gamma^{2}}-\frac{\gamma^{2}\left(2-\gamma^{2}\right) s}{2+\gamma}-(1-\gamma)\left(2+\gamma-2 \gamma^{2}\right)\right) \\
& \times \frac{1}{6-3 \gamma-\gamma^{2}}, \\
t_{B}^{* O}= & \left(\frac{2 \gamma^{3}\left(2-\gamma^{2}\right) c}{6+3 \gamma-\gamma^{2}}-\frac{\gamma^{2}\left(2-\gamma^{2}\right) s}{2+\gamma}-(1-\gamma)\left(2+\gamma-2 \gamma^{2}\right)\right) \\
& \times \frac{1}{6-3 \gamma-\gamma^{2}} .
\end{aligned}
$$

If economic integration is complete $(s=0)$ the optimal tax is negative in the high-cost country for any $c>0$. In the low-cost country the optimal tax is negative for $\gamma$ sufficiently small; for $\gamma$ large enough the optimal tax is negative for small $c$ and positive for large $c$. When economic integration is incomplete $(s>0)$ the optimal tax in the high-cost country is negative for any $c$ but there exists a value of $s$ at which the optimal tax in the low-cost country switches from positive to negative. These results arise because the term multiplying $s$ in the expressions for $t_{B}^{O}$ and $t_{B}^{* O}$ is negative so whenever the optimal tax is negative at $s=0$ it remains negative for $s>0$. On the other hand, when the optimal tax is positive at $s=0$, a high enough $s$ may result in the sign switch. The higher is $s$, the higher is the cut-off value of $c$ above which $t_{B}^{* O}>0$.

The welfare differences are again defined by

$$
\begin{aligned}
& \mu_{B}(\gamma, c, s)=W^{O}(\gamma, c, s)-W^{D}(\gamma, c, s), \\
& \mu_{B}^{*}(\gamma, c, s)=W^{* O}(\gamma, c, s)-W^{* D}(\gamma, c, s),
\end{aligned}
$$

for the high-cost and the low-cost countries respectively. These welfare differences are also quadratic polynomials in $s$, but with different coefficients to those for Cournot competition. An analysis of the coefficients determines the preferences over tax principles. Under Bertrand competition the high cost country prefers the origin tax for all values of $\{\gamma, c, s\}$ for which quantities are positive. This is the same conclusion as obtained for Cournot competition.

The situation of the low-cost country is again more complex. In the Cournot case the low-cost country always preferred the origin principle when there was complete economic integration. This is no longer the case with Bertrand competition. The origin principle is preferred for all values of $c$ if $\gamma$ is small, but with high $\gamma$ the origin principle dominates for the small values of $c$ and the destination principle dominates for large values of $c$. Even complete integration is not enough to guarantee unanimity between countries if the cost difference is large. When economic integration is incomplete, the origin principle is preferred for low values of $c$ and the destination principle for high values of $c$ for any $\gamma$.

These observations are illustrated in Figure 2 for two values of $\gamma$. In both figures the area bounded by the dotted line is the set of $c$ and $s$ for which 

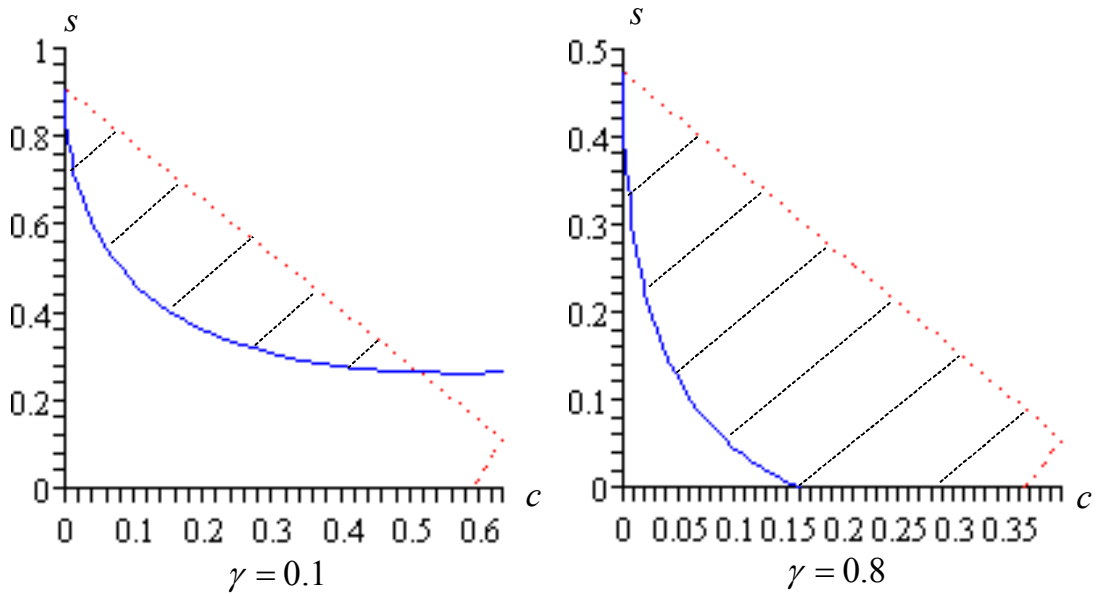

Figure 2: Preferences of the low-cost country (Bertrand)

outputs are positive. The destination principle is preferred for values of $c$ and $s$ in the cross-hatched area above the curve. The origin principle is preferred for parameter combinations below the curve. When $\gamma=0.1$ (so there is limited substitutability between the products) it can be seen that for low values of trade cost the origin principle is always preferred. In this case economic integration will result in agreement between the two countries. This is not the outcome for the right-hand figure which displays a case with greater substitutability $(\gamma=0.8)$. Even with complete integration it is possible for the low-cost country to prefer the destination principle.

The analysis of Bertrand competition provides results that are close in nature to those for Cournot competition but with one significant difference. It remains the case that the high-cost country always prefers the origin principle. What changes is the position when there is complete integration. With Cournot competition complete integration ensured that the countries would also unanimously agree on a preference for origin taxation - any difference in preference that existed when integration was incomplete would eventually be eliminated. In contrast, a difference in preference can persist when there is Bertrand competition. If the countries are sufficiently asymmetric the low-cost country would retain a preference for the destination principle even when trade costs are eliminated. If Bertrand competition is the correct representation of the interaction between firms then the European Union will need both integration and convergence in productivity across countries to ensure unanimous support for the origin principle. 


\section{Size Asymmetry}

A second source of asymmetry between the member states of the European Union is size. Certainly, population size is even more diverse than productivity, and national income reflects this (since the largest and smallest countries have approximately equal income per capita). It is interesting to question how size is reflected in the preference between tax principles.

To focus attention on the implications of the size asymmetry we assume that the countries are equally efficient so set $c=0$. The size of the foreign country is taken as fixed $\left(n^{*}=1\right)$ and the size of the home country is taken as the parameter of interest (with $0<n \leq 1$ ). Hence the home country becomes the small country and the foreign country is the large. As with the case of the cost asymmetry, we restrict the parameters $\{n, s, \gamma\}$ to ensure that there is non-zero trade in equilibrium. Cournot competition is treated first, followed by Bertrand competition.

\subsection{Cournot competition}

The destination principle has the property that the countries choose identical taxes despite the difference in country sizes. The difference in the country size does not matter for the value of the optimal taxes since the variable $n$ enters the objective functions of the two countries uniformly as a scale factor. The optimal taxes are given by

$$
t_{C}^{D}=t_{C}^{* D}=-\frac{s}{2(2-\gamma)} .
$$

The optimal tax for both countries is negative as long as economic integration is incomplete and becomes zero with complete integration. The subsidy is the standard policy response to counter the inefficiency of imperfect competition.

The optimal taxes when the origin principle is in operation are

$$
\begin{aligned}
t_{C}^{O}(n)= & -\frac{4\left(2-\gamma^{2}\right) n^{2}+\left(4+3 \gamma^{2}-2 \gamma^{3}-\gamma^{4}\right) n+2 \gamma^{2}(1-\gamma)}{4\left(2-\gamma^{2}\right)\left(n^{2}+1\right)+\left(\gamma^{4}-13 \gamma^{2}+20\right) n} \\
& +\frac{2-\gamma+\left(4-2 \gamma-\gamma^{2}\right) n}{4\left(2-\gamma^{2}\right)\left(n^{2}+1\right)+\left(\gamma^{4}-13 \gamma^{2}+20\right) n} \frac{2 \gamma^{2} s}{2-\gamma}, \\
t_{C}^{* O}(n)= & t_{C}^{O}\left(\frac{1}{n}\right) .
\end{aligned}
$$

Both taxes are negative for all values of $\{n, s\}$ that ensure positive quantities for a given $\gamma$.

The welfare difference for the large country is defined by

$$
\mu_{C}^{*}(s, \gamma, n)=W^{* O}-W^{* D} .
$$

For given values of $\gamma$ and $n$ the function $\mu_{C}^{*}(s, \gamma, n)$ is a quadratic polynomial in $s$ with a positive coefficient on $s^{2}$. For the range of parameter values for 


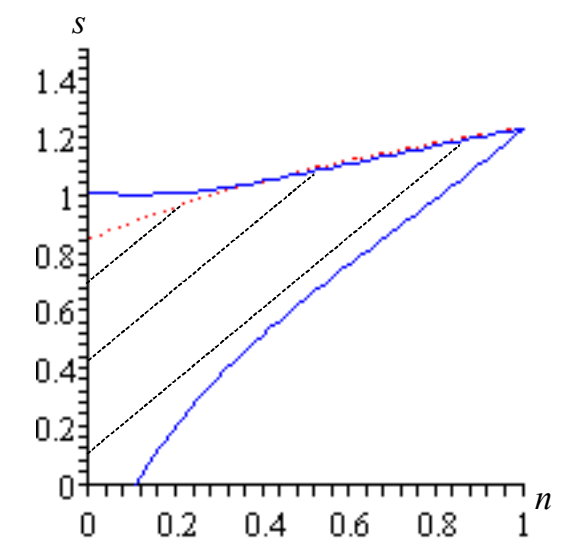

Figure 3: Preferences of the small country (Cournot, $\gamma=0.15$ )

which all quantities are positive the welfare difference $\mu_{C}^{*}(s, \gamma, n)$ is positive. This implies that when there is Cournot competition between firms the large country prefers the origin principle to the destination principle for any $\{n, s, \gamma\}$.

The welfare difference for the small country,

$$
\mu_{C}(s, \gamma, n)=W^{O}-W^{D},
$$

is also a quadratic polynomial in $s$. Analyzing the coefficients of the polynomial shows that for the small country the destination principle is preferred to the origin principle for any $s$ if $n$ is small enough. If $n$ is sufficiently close to 1 then the origin principle dominates for sufficiently high and sufficiently low $s$, and the destination principle dominates for the intermediate values of $s$. These results hold for every $\gamma$.

Figure 3 illustrates the basis for these results. The dotted line is the upper boundary of the set of parameter values for which all quantities are positive. The two curves give the loci of points $\{n, s\}$ that solve $\mu_{C}(s, \gamma, n)=0$ for a given value of $\gamma$ (in this case $\gamma=0.15$ but a similar picture obtains for other values of $\gamma$ ). The welfare difference, $W^{O}-W^{D}$, is positive below the lower branch and above the upper branch, and is negative between the two branches. The small country therefore prefers the destination principle for parameter combinations in the dashed area between the two branches and the origin principle elsewhere.

The size difference causes the two countries to disagree over the choice of taxation principle in a significant proportion of the parameter space. The smaller country prefers the destination principle, and the larger country prefers the origin principle. The larger is the difference in the population sizes, the larger is this area of disagreement. For low values of $n$ (large difference in the population sizes) the welfare difference is always negative, and for the higher values of $n$ it is positive for small $s$ and becomes negative as $s$ increases. For $n$ sufficiently close to 1 a second switch of sign is possible: the welfare difference again becomes 
positive for very high values of $s$.

An important point to note is that there are points with $s=0$ in the area of disagreement. This means that economic integration need not result in convergence of preferences. It will if the countries are similar in size, which is not surprising since this essentially returns the analysis to the symmetric case. Size differences can remain an impediment to agreement.

\subsection{Bertrand competition}

With Bertrand competition in the second stage and the destination principle the equilibrium is symmetric regardless of the difference in the country sizes. This is because under the destination principle the size of the small country, $n$, enters the objective functions of both countries as a scale factor so and the solution does not depend on $n$. The optimal taxes for the destination principle are

$$
t_{B}^{D}=t_{B}^{* D}=-\frac{(1+\gamma) s}{2(2+\gamma)}
$$

It is clear from (22) that the optimal tax for both countries is negative as long as trade costs are positive $(s>0)$.

The optimal taxes if the origin principle applies are

$$
\begin{aligned}
t_{B}^{O}(n)= & -\left[\left((2 n+1)(2+\gamma)-n \gamma^{2}\right) \frac{\left(2-\gamma^{2}\right) \gamma^{2}}{2+\gamma} s\right. \\
& +(1-\gamma)\left(4(n+2)(2 n+1)(1+\gamma)+(n+1) \gamma^{4}\right) \\
& \left.-(1-\gamma)\left(\left(4 n^{2}+5 n+2\right) \gamma^{2}-n(4 n+3) \gamma^{3}\right)\right] \\
& \times \frac{1}{4(n+2)(2 n+1)-\left(4 n^{2}+13 n+4\right) \gamma^{2}+n \gamma^{4}} \\
t_{B}^{* O}(n)= & t^{O}\left(\frac{1}{n}\right) .
\end{aligned}
$$

It can be deduced that $t_{B}^{* O}$ is always negative, whereas $t_{B}^{O}$ is negative for $s>$ $\widehat{s}(\gamma, n)$ and positive for $0<s<\widehat{s}$ where $\widehat{s}(\gamma, n)$ is positive for small values of $n$. Therefore, under the origin principle the optimal tax for the large country is negative for any $\{n, s, \gamma\}$ and there exists a value of $s$ at which the optimal tax for the small country switches from negative (at low $s$ ) to positive (at high $s$ ).

The welfare difference for the large country is given by

$$
\mu_{B}^{*}(s, \gamma, n)=W^{* O}-W^{* D} .
$$

For given values of $\gamma$ and $n$ the function $\mu_{B}^{*}(s, \gamma, n)$ is a quadratic polynomial in $s$ with positive coefficient on $s^{2}$. Both the roots of the equation lie outside the set of parameter values that ensure quantities are positive, and inside the set $\mu_{B}^{*}(s, \gamma, n)$ is positive. These observations imply that when there is Bertrand competition the large country prefers the origin principle to the destination principle for any $\{n, s, \gamma\}$. 


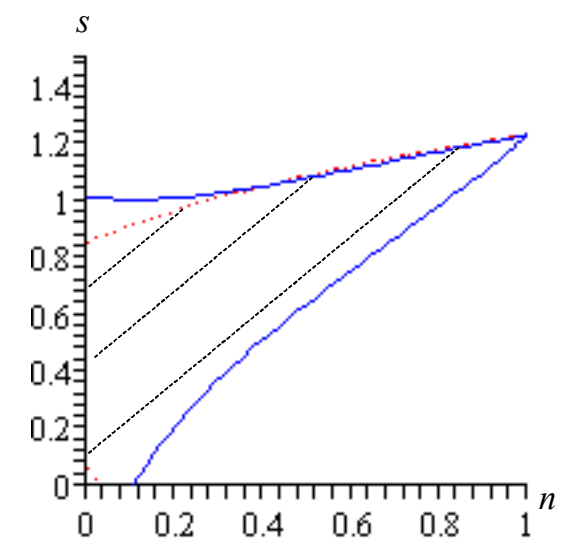

Figure 4: Preferences of the small country (Bertrand, $\gamma=0.05$ )

The welfare difference for the small country,

$$
\mu_{B}(s, \gamma, n)=W^{O}-W^{D},
$$

is also a quadratic polynomial in $s$. Analyzing this polynomial shows that the small country prefers the destination principle to the origin principle for any $s$ if $n$ is small enough. If $n$ is sufficiently close to 1 then the origin principle is preferred for $s$ sufficiently high and sufficiently low, and the destination principle is preferred for intermediate values of $s$.

Figure 4 illustrates the welfare difference for the small country. The dotted line is the boundary of the set of parameter values which guarantee all quantities are positive. The value of the welfare difference $\mu^{B}(s, \gamma, n)$ is positive below the lower branch and above that part of the upper branch that is below the boundary shown by the bold line, and is negative between the two branches. Hence, in the cross-hatched area the small country prefers the destination regime. As a consequence the two countries disagree for the parameter values between the branches over which tax principle should be chosen since the large country always prefers the origin principle.

The figure also shows that for small values of $n$ the welfare difference is negative at $s=0$. This is a feature of the Bertrand case for all values of $\gamma$. The implication of this fact is that the disagreement between the countries is not resolved by economic integration. Even when trade costs are entirely eliminated size differentials can still remain a source of disagreement.

\section{Conclusions}

The literature on the choice between the origin and destination principles of taxation has focused primarily upon economies with symmetric countries. We 
have argued that there is considerable asymmetry among the member states of the European Union, which raises questions concerning the policy relevance of existing results. These observations have motivated our study of whether the preference between tax principles can be related to the characteristics of countries. The model considered two sources of asymmetry: efficiency in production and size of market. The analysis has demonstrated that there are very clear links between characteristics and the preferences over tax principles.

The first source of asymmetry we considered was a difference in production efficiency between countries. The degree of efficiency was represented by the marginal cost of production and, in our two country world, one country was assigned a low cost and the other a high cost. For both Cournot and Bertrand competition the high-cost country preferred the origin principle to the destination principle. In contrast, the low-cost country prefers the origin principle in some circumstances, and the destination principle in others. In particular, the destination principle is preferred when the cost differential between the countries is large.

This potential absence of agreement between countries is a consequence of the asymmetry since it does not arise in the symmetric case. Disagreement is possible with both forms of competition between firms but there is an important distinction. When there is Cournot competition the countries will converge on a preference for the origin principle as economic integration proceeds. With complete integration both countries will prefer the origin principle. This is not necessarily the case when there is Bertrand competition and the disagreement can remain even with complete integration if the cost difference between countries is large.

The second source of asymmetry was a difference in country size. This was represented by the countries having different numbers of consumers. With a size difference modelled in this way it was shown that the large country always preferred the origin principle. The preference of the small country between the principles depended upon the location in the parameter space. For a range of values of trade cost and size difference, notably including zero trade cost, the small country preferred the destination principle. This difference between the structure of preferences for the two countries again allows for disagreement. More importantly, complete economic integration does not remove the disagreement for any configuration of parameters.

In brief, these result show that large countries and inefficient countries prefer the origin principle in all cases. The preference of small countries and efficient countries is dependent upon the parameter configuration. Any disagreement between countries is removed by economic integration if competition between firms is in quantities or the efficiency difference not too large. But disagreement over preferred principle as a consequence of size is not removed by economic integration. Therefore, country size remains a more fundamental source of disagreement over the choice of tax principle.

What implications do these results have for our understanding of economic policy? The European Union is a diverse collection of countries, with the diversity enhanced by the recent addition of new member states. The European 
Commission has a long-standing intention to move to the origin principle but no progress has been made in this direction since the completion of the single market. This lack of progress seems surprising given what symmetric models say about the unanimity of preference for the origin principle in models of imperfect competition. However, symmetry among countries is a poor approximation to the position in the European Union. Countries vary considerably in size and in productivity, and it seems important to confront the preference for the origin principle with these differences. In conclusion, the results predict that the degree of asymmetry in the European Union is going to remain an impediment to progress toward a political consensus on the tax principle for trade within the union. The European Union does seem to have reached a impasse on this issue. The analysis shows why this is the case, and demonstrates how insurmountable it may prove to be.

\section{References}

Brander, J. A. and B. Spencer, 1985, "Export subsidies and international market share rivalry", Journal of International Economics, 18, 83 - 100.

Hashimzade, H., H. Khodavaisi and G.D. Myles 2005, "Tax principles, product differentiation and the nature of competition", International Tax and Public Finance, 12, 695 - 712.

Haufler, A. and G. Schjelderup and F. Stahler, 2005, "Barriers to trade and imperfect competition: the choice of commodity tax base", International Tax and Public Finance, 12, 281 - 300.

Keen, M. and S. Lahiri , 1998, "The comparison between destination and origin principles under imperfect competition", Journal of International Economics, 45, 323 - 350 .

Lockwood, B., D. de Meza and G. D. Myles, 1994a, "When are origin and destination regimes equivalent?", International Tax and Public Finance, 1, 5 24.

Lockwood, B., D. de Meza and G. D. Myles, 1994b, "The equivalence between destination and non-reciprocal restricted origin tax regimes", Scandinavian Journal of Economics, 96, 311 - 328.

Neary, J. P. 1994, "Cost asymmetries in international subsidy games: should governments help winners or losers?", Journal of International Economics, 37, $197-218$.

Tinbergen, J. (1953) Report on the Problems Raised by Value Added Taxation in the Common Market (European Coal and Steel Community - High Authority).

Vives, X., 1984, "Duopoly information equilibrium: Cournot and Bertrand", Journal of Economic Theory, 34, 71 - 94. 